\title{
LEARNING TO INCENTIVIZE IN DIFFERENT MODES OF COORDINATION
}

\author{
FRIEDERIKE WALL \\ Department of Management Control and Strategic Management, \\ Alpen-Adria-Universitaet Klagenfurt, \\ Universitaetsstrasse 65-67, 9020 Klagenfurt, Austria \\ friederike.wall@aau.at
}

Received 20 November 2016

Revised 4 April 2017

Accepted 23 June 2017

Published 25 July 2017

\begin{abstract}
The paper studies which incentive systems emerge in organizations when self-interested managers collaboratively search for higher levels of organizational performance and the headquarters learn about the success of the incentive systems employed. The study uses an agent-based simulation and, in particular, controls for different levels of intra-organizational complexity and modes of coordination, i.e., the way how preferences on the departmental site are aligned with each other in respect to the overall organizational objective. The results indicate that for different levels of intra-organizational complexity different incentive systems emerge: With lower intra-organizational complexity, in tendency, the less focus is put on firm performance and vice versa. However, results also suggest that the mode of coordination may considerably affect the emergence of the incentive structure. This provides support for the idea that multiple management controls, like the incentive system and the mode of coordination, should be regarded and designed as a system with interrelations among its components and not just as a collection of several control practices.
\end{abstract}

Keywords: Complexity; coordination; incentives; multiple management controls; NK landscapes; reinforcement learning.

\section{Introduction}

The question of how to incentivize managers to make decisions that are in the firm's or its owners' interest is a core issue in managerial science; the theoretical foundations reach from, for example, motivational theories in psychology (e.g., [20, 26]) to contract theory with its roots in information economics [22]. In the latter, the analysis of incentive systems employing closed-form models based on principal-agent theory predominates [14]. With this, incentive systems usually are investigated

This is an Open Access article published by World Scientific Publishing Company. It is distributed under the terms of the Creative Commons Attribution 4.0 (CC-BY) License. Further distribution of this work is permitted, provided the original work is properly cited. 
in equilibrium, i.e., when contracting parties have agreed on a certain contract (comprising the incentive system) and under conditions of rather gifted agents (e.g., knowing the entire solution space of their decision problem in advance) [9, 40]. Moreover, a common (mostly implicit) assumption in principal-agent based research on reward structures is that the agent (manager) to whom a decision is delegated is in charge of finally making this decision — without any coordination with other managers or the headquarters (principal). With this, potential interactions of incentive systems with other management control practices like the mode of coordination (e.g., $[12,34,36])$ are of minor relevance in the stream of research based on principal-agent theory.

This paper takes a different perspective, first, with respect to managers' and headquarters' cognitive capabilities, and, second, in regarding incentive systems as one component of management control systems:

(1) In view of cognitive capabilities, this paper studies situations where selfinterested managers and the headquarters have imperfect and heterogeneous knowledge of the solution space of the organization's overall decision problem and cannot perfectly evaluate the possible solutions in advance (e.g., [9, 15, 17, 33, 37]). With this, the headquarters is not able to identify the optimal incentive system in advance (unlike assumed in principal-agent theory); rather, in the course of the organization's search for higher levels of overall performance the headquarters learns about incentivizing managers.

(2) There is some evidence that management control practices (like the incentive system and the mode of coordination as mentioned above) employed in an organization may be rather a system than merely a collection: in this context the term "system" means that interactions among management control practices may exist and, thus, the internal consistency among control practices is of relevance. Moreover, there is some evidence that the fit of management control practices to a set of contingencies like, for example, the complexity of an organization's task is of relevance $[5,10,13,18,28,30]$.

Hence, in this paper, the incentive system of an organization is studied as evolving over time through learning under different modes of coordination and conditions of complexity. With this, the paper seeks to make a step towards a two-fold research objective: First, obviously it is of interest which incentive systems may emerge under different conditions of, for example, intra-organizational complexity and under more sophisticated coordination modes - features which are hardly to analyze simultaneously in closed-form models of principal-agent research [9, 40]. Second, relaxing assumptions on agents' cognitive capabilities and on the virtual absence of coordination beyond the incentive system (as typically incorporated in principal-agent research) allows studying to what extent the findings of research based on these assumptions are robust in settings with less gifted agents and more sophisticated coordination modes $[3,11,19]$.

For this purpose, the study employs an agent-based simulation model which captures two intertwined adaptive processes: (1) In the short term, the artificial 
organizations search for superior levels of overall performance; (2) in the mid term, the organizations adapt the incentive system via learning by reinforcement based on the performance enhancements achieved. In particular, the organizations learn whether rewarding departmental managers according to their units' performance only or whether compensating firm performance is more appropriate; in the latter case, obviously, the incentive system may provide some cross-unit coordination. Hence, an interesting question is how the coordinative effects of the evolving incentive system interact with what is named here the mode of coordination, i.e., the way of how departmental preferences are aligned and how the final choices are made. Therefore, the simulation experiments differentiate for different levels of task complexity — and, by that, varying the need for coordination — and for different coordination modes.

\section{Simulation Model}

\subsection{Overview of the organizational set-up}

The organizations simulated consist of the headquarters and $M$ departments. ${ }^{\text {a }}$ Each department $r, r=1, \ldots, M$ has a department head which is compensated according to a linear incentive scheme $[4,8,31]$ and that seeks to maximize compensation. An organization strives for superior solutions for an $N$-dimensional decision problem which is partitioned into $M$ disjoint partial problems $N^{r}$. Each of these sub-problems is delegated to one unit $r$ — with the particular competencies of manager $r$ related to sub-problem $N^{r}$ being subject to the coordination mode. Hence, depending on the coordination mode employed, the departments are, at least, preparing choices regarding their partition of the overall $N$-dimensional decision problem in each period $t$ of an adaptive walk.

In the end of each period, the headquarters register the performance levels achieved and compensate the unit heads according to the incentive scheme. Moreover, in each $T^{*}$ th period, the headquarters assess the performance enhancement achieved within the last $T^{*}$ periods and, eventually, modify the incentive system according to the result of this assessment. In particular, the propensities to keep the current incentive system or to modify the incentive structure are adjusted according to the performance enhancements achieved following a simple model of statistical learning, i.e., a generalized form of the Bush-Mosteller model $[6,7]$.

\subsection{Organizational decision problem based on NK fitness landscapes}

The organizations captured in the model face an $N$-dimensional binary decision problem which follows the framework of NK-fitness landscapes as originally introduced in the domain of evolutionary biology [21] and, since then, broadly employed in managerial science (for an overview see [40]). A major feature of NK fitness landscapes is that they allow to easily control for the complexity of the

a A list of symbols is displayed in the appendix in Table A.1. 
$N$-dimensional decision problem captured by parameter $K$ and, "technically", are stochastically generated pseudo-boolean functions with $N$ bits, i.e., $F:\{0,1\}^{N} \rightarrow \mathbb{R}^{+},[25]$.

In particular, in each time step an organization seeks to find a superior configuration $\mathbf{d}_{t}$ of an $N$-dimensional binary decision problem, i.e., $\mathbf{d}_{t}=\left(d_{1 t}, \ldots, d_{N t}\right)$ with $d_{i t} \in\{0,1\}, i=1, \ldots, N$, out of $2^{N}$ different binary vectors possible. Each of the two states $d_{i t} \in\{0,1\}$ contributes with $C_{i t}$ to overall organizational performance $V\left(\mathbf{d}_{t}\right)$. In line with the NK framework, $C_{i t}$ is randomly drawn from a uniform distribution with $0 \leq C_{i t} \leq 1$.

The parameter $K$ (with $0 \leq K \leq N-1$ ) reflects the number of those choices $d_{j t}$, $j \neq i$ which also affect the performance contribution $C_{i t}$ of choice $d_{i t}$. Hence, contribution $C_{i t}$ may not only depend on the single choice $d_{i t}$, but also on $K$ other choices:

$$
C_{i t}=f_{i}\left(d_{i t} ; d_{i_{1} t}, \ldots, d_{i_{K} t}\right),
$$

with $\left\{i_{1}, \ldots, i_{K}\right\} \subset\{1, \ldots, i-1, i+1, \ldots, N\}$.

In case of no interactions among choices, $K$ equals 0 , and $K$ is $N-1$ for maximum interactions where each single choice $i$ affects the performance contribution of each other binary choice $j \neq i$. (With this, the number of different random numbers to be drawn for the $C_{i t}$ for each single choice $i$ depends on the level of $K$ and is given by $2^{K+1}$; for an entire landscape $N \cdot 2^{K+1}$ different random numbers are required $[1,25]$.)

The overall performance $V_{t}$ achieved in period $t$ results as normalized sum of contributions $C_{i t}$ from

$$
V_{t}=V\left(\mathbf{d}_{t}\right)=\frac{1}{N} \sum_{i=1}^{N} C_{i t} .
$$

\subsection{Departmental options and their evaluation}

As mentioned above each department $r$ is in charge of making or, at least, preparing choices on a sub-problem $N^{r}$ which is assigned to this department. Hence, from the unit head $r$ 's perspective, the overall problem is segmented in a partial problem $\mathbf{d}_{t}^{r}$ which is in her/his own primary control and into a partial vector $\mathbf{d}_{t}^{r \text {,res }}$ for the residual choices that the other department heads $q \neq r$ are in charge of. However, in case of cross-segment interactions among the sub-problems - captured by $K^{*}<0$, choices of manager $r$ might affect the contribution of the other managers' choices on overall performance, and vice versa.

In each time step $t$, a manager seeks to identify the best configuration for the "own" choices $\mathbf{d}_{t}^{r}$. In particular, in each time step $t$ manager $r$ randomly discovers two alternatives to status quo $\mathbf{d}_{t-1}^{r *}$ - an alternative configuration $\mathbf{d}_{t}^{r, a 1}$ that differs in one choice $(a 1)$ and another alternative $\mathbf{d}_{t}^{r, a 2}$ where two bits $(a 2)$ are flipped. Hence, in each time step head of department $r$ has three options (including staying with the status quo). 
Next, each unit head $r$ compiles a preference list of these three options $L_{t}^{r}=$ $\left\{\mathbf{d}_{t}^{r, p 1}, \mathbf{d}_{t}^{r, p 2}, \mathbf{d}_{t}^{r, p 3}\right\}$ where $\mathbf{d}_{t}^{r, p 1}$ indicates the most preferred option out of $\mathbf{d}_{t-1}^{r *}, \mathbf{d}_{t}^{r, a 1}$ and $\mathbf{d}_{t}^{r, a 2}$. Correspondingly, $\mathbf{d}_{t}^{r, p 2}$ denotes the second-most and $\mathbf{d}_{t}^{r, p 3}$ the third-most preferred option. For the first formation ${ }^{\mathrm{b}}$ of preferences at time step $t$, unit $r$ assumes that the other departments $q \neq r$ will stay with the status quo, i.e., $\mathbf{d}_{t-1}^{q *}$ (for this see also [2]).

The preferences of unit head $r$ depend on how the options promise to affect the manager's value base for compensation $P_{t}^{r}\left(\mathbf{d}_{t}\right)$ and with this the incentive system comes into play: The model captures a linear reward structure in which depending on parameter $\alpha$ - the manager may focus only on the "own" partial problem or may, at least partially, consider the residual part of the decision problem, too [36] (Eq. (3)):

$$
P_{t}^{r}\left(\mathbf{d}_{t}\right)=P_{t}^{r, \text { own }}\left(\mathbf{d}_{t}^{r}\right)+\alpha_{t}^{r} \cdot P_{t}^{r, \text { res }}
$$

where

$$
\begin{gathered}
P_{t}^{r, \text { own }}\left(\mathbf{d}_{t}^{r}\right)=\frac{1}{N} \sum_{i=1+w}^{N^{r}} C_{i t}, \\
P_{t}^{r, \text { res }}=\sum_{q=1, q \neq r}^{M} P_{t}^{q, \text { own }}
\end{gathered}
$$

and with $w=\sum_{s=1}^{r-1} N^{s}$ for $r>1$ and $w=0$ for $r=1$.

The managers' ex ante evaluations of options do not necessarily need to be perfect, i.e., the managers may misjudge their options' contributions to their value base of compensation $P_{t}^{r}$. In particular, due to specialization, the ex ante evaluation of the options' effects on a unit head's own partial decision problem $N^{r}$ may be more precise than the evaluation of effects on the rest of the organization. To incorporate this aspect in the model, the managers are endowed with distorted information for ex ante evaluation about the contributions of options which is captured by adding error terms as shown in Eq. (6):

$$
\tilde{P}_{t}^{r}\left(\mathbf{d}_{t}\right)=\tilde{P}_{t}^{r, \text { own }}\left(\mathbf{d}_{t}^{r}\right)+\alpha^{r} \cdot \tilde{P}_{t}^{r, \text { res }}
$$

where

$$
\begin{gathered}
\tilde{P}_{t}^{r, \text { own }}\left(\mathbf{d}_{t}^{r}\right)=P_{t}^{r, \text { own }}\left(\mathbf{d}_{t}^{r}\right)+e^{r, \text { own }}\left(\mathbf{d}_{t}^{r}\right), \\
\tilde{P}_{t}^{r \text {,res }}\left(\mathbf{d}_{t}^{r, \text { res }}\right)=P_{t}^{r \text {,res }}\left(\mathbf{d}_{t}^{r, \text { res }}\right)+e^{r, \text { res }}\left(\mathbf{d}_{t}^{r, \text { res }}\right) .
\end{gathered}
$$

For the sake of simplicity, distortions are depicted as relative errors imputed to the true performance. The error terms follow a Gaussian distribution $N(0 ; \sigma)$ with

\footnotetext{
${ }^{b}$ Depending on the coordination mode, the once formed preferences may be revised after a unit learns about other units' preferences. For an overview, see Table 1, particularly column "Second evaluation of units' preferences". For the coordination modes, see Sec. 2.4.
} 
expected value 0 and standard deviations $\sigma^{r \text {,own }}$ and $\sigma^{r \text {,res }}$; errors are assumed to be independent from each other.

Although, for the sake of simplicity, $\sigma^{r, \text { own }}$ and $\sigma^{r, \text { res }}$ are assumed to be the same for all managers $r$ and stable in time, this means that each manager $r$ has a distinct "view" of the true fitness landscape: since each manager $r$ is exclusively in charge of an "own" part of the entire $N$-dimensional decision problem, while the "rest" is assigned to other departments, the error terms $\sigma^{r \text {,own }}$ and $\sigma^{r \text {,res }}$ relate - for each department head $r$ - to another fragment of the entire problem. Thus, the model captures $M+1$ heterogeneous (distorted) views of the true landscape, i.e., one view per unit $r=1, \ldots, M$ and the headquarters' perspective.

Hence, as a result of the departmental search and (potentially imprecise) ex ante evaluation of options, each department has an ordered list $L_{t}^{r}=\left\{\mathbf{d}_{t}^{r, p 1}, \mathbf{d}_{t}^{r, p 2}, \mathbf{d}_{t}^{r, p 3}\right\}$ of preferences.

\subsection{Modes of coordination}

After the unit heads have formed their preferences related to the options on their partial decision vector $\mathbf{d}_{t}^{r}$, the next step within each period $t$ is to come to a decision on the organization's overall decision problem $\mathbf{d}_{t}$. For this, the model comprises four different modes of coordination, i.e., modes of how the unit heads' preferences on $\mathbf{d}_{t}^{r}$ captured in the $M$ lists $L_{t}^{r}$ are transformed into the final choice of the entire configuration $\mathbf{d}_{t}$. Table 1 summarizes major features of the modes of coordination captured in the simulation model.

\subsubsection{Decentralized mode}

The least intense coordination among units $r$ - or the highest level of departmental autonomy — is implemented if each unit is allowed to choose its most preferred option. Then, the overall organizational configuration $\mathbf{d}_{t}$ results from

$$
\mathbf{d}_{t}=\left(\mathbf{d}_{t}^{1, p 1}, \ldots, \mathbf{d}_{t}^{r, p 1}, \ldots, \mathbf{d}_{t}^{M, p 1}\right) .
$$

Hence, in this mode of coordination, the partial option implemented in unit $r$ is given by

$$
\mathbf{d}_{t}^{r *}=\mathbf{d}_{t}^{r, p 1} \quad \forall r \in\{1, \ldots, M\} .
$$

Obviously, for making the final choice of $\mathbf{d}_{t}$ the "decentralized" mode does not require any form of communication between units or of the units with the headquarters. Moreover, the role of the headquarters is confined to, in the end of period $t$, registering the achieved performance of the $\mathbf{d}_{t}$ and to compensating the unit heads accordingly.

\subsubsection{Sequential mode}

In the sequential mode of coordination, the units make their choices sequentially where, for the sake of simplicity, the sequence is given by the index $r$ of the units. 
Table 1. Overview of modes of coordination of the simulation model.

\begin{tabular}{|c|c|c|c|c|}
\hline $\begin{array}{l}\text { Coordination } \\
\text { mode }\end{array}$ & $\begin{array}{c}\text { Communication } \\
\text { of units' } \\
\text { preferences }\end{array}$ & $\begin{array}{l}\text { Second evaluation } \\
\text { of units' options }\end{array}$ & $\begin{array}{l}\text { Headquarters } \\
\text { intervenes in } \\
\text { decision-making }\end{array}$ & $\begin{array}{l}\text { Resulting units' configura- } \\
\text { tions } \mathbf{d}_{t}^{r *} / \text { condition }\end{array}$ \\
\hline Decentralized & no & no & no & $\begin{array}{l}\text { first preference } \mathbf{d}_{t}^{r, p 1} \\
\qquad \forall r \in\{1, \ldots, M\}\end{array}$ \\
\hline Sequential & $\begin{array}{l}\text { yes, to "next" } \\
\text { unit }\end{array}$ & $\begin{array}{l}\text { yes, for } r>1 \text { by } \\
\text { unit } r\end{array}$ & no & $\begin{array}{l}\text { first preference depending } \\
\text { on the previous units' } \\
\text { choices } \mathbf{d}_{t}^{r, p 1}\left(\mathbf{d}_{t}^{r-1, p 1}\right) \text { for } \\
r>1 ; \mathbf{d}_{t}^{r, p 1} \text { for } r=1\end{array}$ \\
\hline $\begin{array}{l}\text { Horizontal } \\
\text { veto }\end{array}$ & $\begin{array}{l}\text { yes, to all other } \\
\text { units } q \neq r\end{array}$ & $\begin{array}{l}\text { yes, by unit } r \text { and, } \\
\text { depending on } \\
\text { incentives } \alpha, \\
\text { also by other } \\
\text { units } q \neq r\end{array}$ & no & $\begin{array}{l}\text { first [or second] preference } \\
\qquad \begin{array}{l}\mathbf{d}_{t}^{r, p 1}\left[\text { or } \mathbf{d}_{t}^{r, p 2}\right] \text { if com- } \\
\text { posite vector } \mathbf{d}^{C} \text { pro- } \\
\text { mises, at least, salary of } \\
\text { status quo, i.e., if } \\
\tilde{P}\left(\mathbf{d}^{C}\right) \geq \tilde{P}\left(\mathbf{d}_{t-1}\right) \forall r ; \\
\text { otherwise } \mathbf{d}_{t}^{r *}=\mathbf{d}_{t-1}^{r *}\end{array}\end{array}$ \\
\hline Proposal & $\begin{array}{l}\text { yes, to head- } \\
\text { quarters }\end{array}$ & $\begin{array}{l}\text { yes, by head- } \\
\text { quarters }\end{array}$ & yes & $\begin{array}{l}\text { first [or second] preference } \\
\qquad \begin{array}{l}\mathbf{d}_{t}^{r, p 1}\left[\text { or } \mathbf{d}_{t}^{r, p 2}\right] \text { if com- } \\
\text { posite vector promises, } \\
\text { at least, firm perfor- } \\
\text { mance of status quo i.e., } \\
\text { if } \tilde{V}\left(\mathbf{d}^{C}\right) \geq V\left(\mathbf{d}_{t-1}\right) ; \\
\text { otherwise } \mathbf{d}_{t}^{r *}=\mathbf{d}_{t-1}^{r *}\end{array}\end{array}$ \\
\hline
\end{tabular}

In particular, in time step $t$ unit $r$ with $1<r \leq M$ is informed by unit $r-1$ about the choices made so far, i.e., made by the "preceding" units $<r$. Unit $r$ takes these choices into account and re-evaluates the "own" options $\mathbf{d}_{t-1}^{r *}, \mathbf{d}_{t}^{r, a 1}$ and $\mathbf{d}_{t}^{r, a 2}$ (Eqs. (3) and (6), respectively) - potentially resulting in an adjusted list of preferences $L_{t}^{r}=\left\{\mathbf{d}_{t}^{r, p 1}, \mathbf{d}_{t}^{r, p 2}, \mathbf{d}_{t}^{r, p 3}\right\}$ and chooses $\mathbf{d}_{t}^{r, p 1}$ which here depends on $\mathbf{d}_{t}^{r-1, p 1}$, i.e., is a function of the choices of the preceding units. Obviously, only unit 1 does not have to take a previous choice into account. Hence, the choice of unit $r=(1, \ldots, M)$ is made according to

$$
\mathbf{d}_{t}^{r *}= \begin{cases}\mathbf{d}_{t}^{r, p 1} & \text { if } r=1 \\ \mathbf{d}_{t}^{r, p 1}\left(\mathbf{d}_{t}^{r-1, p 1}\right) & \text { if } 1<r \leq M\end{cases}
$$

and with Eq. (11), the overall configuration results from

$$
\mathbf{d}_{t}=\mathbf{d}_{t}^{M *} .
$$

In the sequential mode, the headquarters does not intervene in decision-making and is confined to observing the performance $V\left(\mathbf{d}_{t}\right)$ achieved and compensating the unit heads according to the incentive system. 


\subsubsection{Horizontal veto mode}

The unit heads mutually inform each other about their most preferred options $\mathbf{d}_{t}^{r, p 1}$. Next, each unit head individually evaluates the composite vector $\mathbf{d}^{C}=$ $\left(\mathbf{d}_{t}^{1, p 1}, \ldots, \mathbf{d}_{t}^{r, p 1}, \ldots, \mathbf{d}_{t}^{M, p 1}\right)$ (i.e., the configuration which results from the first preferences of all $M$ units) according to the incentive system and based on that unit head's individual knowledge (due to specialization) as captured in Eq. (6). However, the unit heads are endowed with mutual veto power. Thus, since no department head would accept a reduction in salary compared to the previous period, the composite vector $\mathbf{d}^{C}$ requires to, at least, promise the same compensation as the status quo $\mathbf{d}_{t-1}$ to each single unit head. Hence, the composite vector $\mathbf{d}^{C}$ has to meet the following condition

$$
\tilde{P}_{t}^{r}\left(\mathbf{d}^{C}\right) \geq \tilde{P}_{t}^{r}\left(\mathbf{d}_{t-1}\right) \quad \forall r \in\{1, \ldots, M\}
$$

to be accepted (i.e., for that $\mathbf{d}_{t}=\mathbf{d}^{C}$ ). If, at least, one unit head vetoes (i.e., if the condition in Eq. (13) is not met) then the units' second preferences are composed to $\mathbf{d}^{C}=\left(\mathbf{d}_{t}^{1, p 2}, \ldots, \mathbf{d}_{t}^{r, p 2}, \ldots, \mathbf{d}_{t}^{M, p 2}\right)$, evaluated according to Eq. (6) by each unit and assessed according to Eq. (13). If this option does not meet the condition in Eq. (13), then the status quo is kept, i.e., then $\mathbf{d}_{t}=\mathbf{d}_{t-1}$.

In this mode of coordination, the headquarters have the likewise limited role as in the decentralized and the sequential mode.

\subsubsection{Proposal mode}

Each unit transfers its list $L_{t}^{r}$ of preferences to the headquarters. The headquarters compiles the first preferences to a composite vector $\mathbf{d}^{C}=\left(\mathbf{d}_{t}^{1, p 1}, \ldots, \mathbf{d}_{t}^{r, p 1}, \ldots, \mathbf{d}_{t}^{M, p 1}\right)$ and evaluates the organizational performance it promises. However, like the departments, the headquarters is not able to perfectly ex ante evaluate options. For the sake of simplicity, the headquarters' imprecision is captured by an error term $e^{\text {head }}\left(d_{t}\right)$ being normally distributed with expected value 0 , standard deviation $\sigma^{\text {head }}$ and being independent from the units' error terms. The headquarters' ex ante evaluation of option $\mathbf{d}^{C}$ with respect to organizational performance $V\left(\mathbf{d}_{C}\right)$ follows from

$$
\tilde{V}\left(\mathbf{d}^{C}\right)=V\left(\mathbf{d}^{C}\right)+e^{\text {head }}\left(\mathbf{d}^{C}\right) .
$$

The headquarters decides in favor of the composite vector, i.e., $\mathbf{d}_{t}=\mathbf{d}^{C}$, if $\mathbf{d}^{C}$ promises the same or a higher performance as the status quo $\mathbf{d}_{t-1}$ :

$$
\tilde{V}\left(\mathbf{d}^{C}\right) \geq V\left(\mathbf{d}_{t-1}^{*}\right) .
$$

If the composite vector $\mathbf{d}^{C}$ assembled from the units' first preferences does not meet the condition in Eq. (15), the headquarters evaluates a vector composed from the units' second preferences according to Eq. (15). If this also does not, at least, promise the performance of the status quo, then the organizations stay with the status quo, i.e., then $\mathbf{d}_{t}=\mathbf{d}_{t-1}$. 


\subsection{Learning-based adjustment of incentive systems}

In the end of each time step $t$, the headquarters assesses the performance enhancements of the choices made — depending on the mode of coordination — by the departments or the headquarters and compensates the unit heads according to the incentive system. Moreover, from time to time, the headquarters may adjust the incentive system. In particular, in each $T^{*}$ th time step, the headquarters learns via reinforcement about the success of the incentive system in terms of performance enhancements achieved. More technically speaking, the headquarters updates the propensities of the alternative incentive systems to be chosen for the next $T^{*}$ periods and, eventually, alters the incentive system (as controlled by the updated propensities).

For this, the model employs a simple mode of reinforcement learning based on statistical learning, i.e., a generalized form of the Bush-Mosteller model [6, 7]: Let $\phi_{t}=\left(\alpha^{1}(t), \ldots, \alpha^{M}(t)\right)$ denote the configuration of the incentives given to the $M$ unit heads in $t$, where $\alpha^{r}$ captures the ratio to which unit $r$ is rewarded according to the performance achieved in the rest of the organization - additionally to its departmental performance (see Eqs. (3) and (6), respectively). For the sake of simplicity, in the simulation experiments $\alpha^{r}(t)$ is the same for all department heads $r=1, \ldots, M$. Therefore, subsequently, configuration $\phi_{t}$ can be addressed just by a level $\alpha$ implemented in $t$, denoted by $\alpha(t)$, which is applied to the heads of all units $r$.

The incentive system $\alpha(t)$ is selected from a set $A=\left\{\alpha^{1}, \ldots, \alpha^{a}, \ldots, \alpha^{|A|}\right\}$ (with $1 \leq a \leq|A|)$ of possible incentive systems captured by different levels of $\alpha \cdot p\left(\alpha^{a}, t\right)$ denotes the probability of an alternative $\alpha^{a}$ to be chosen at time $t$ (with $0 \leq$ $p\left(\alpha^{a}, t\right) \leq 1$ and $\left.\sum_{\alpha^{a} \in A}\left(p\left(\alpha^{a}, t\right)\right)=1\right)$.

In every $T^{*}$ th period, the propensities $p\left(\alpha^{a}, t+1\right)$ for the "next" incentive system (i.e., implemented in the next $T^{*}$ periods) are updated according to the - positive or negative - stimuli resulting from the outcome (pay-off) $\omega$ of the prior choice of the incentive system (made in $t-T^{*}$ ), i.e., the outcome of the incentive system $\alpha(t)=\alpha^{a}$ currently employed. Whether $\omega_{t}(\alpha(t))$ at time step $t$ is regarded positive or negative, depends on whether, or not, it, at least, equals an aspiration level $v$ where outcome $\omega_{t}$ of incentive system $\alpha(t)$ is the relative performance enhancement achieved within the last $T^{*}$ periods, i.e.,

$$
\omega_{t}(\alpha(t))=\frac{V_{t}-V_{t-T^{*}}}{V_{t-T^{*}}} .
$$

Hence, the feedback $\tau(t)$ of this evaluation is

$$
\tau(t)= \begin{cases}1 & \text { if } \omega_{t}(\alpha(t)) \geq v \\ -1 & \text { if } \omega_{t}(\alpha(t))<v\end{cases}
$$

If the feedback is positive $(\tau(t)=1)$, then the propensity of the current incentive system $\alpha(t)$ to be chosen for the next $T^{*}$ periods is increased and the propensities of the other incentive systems are decreased; in contrast, in case of negative feedback, 
the propensity of the current incentive system $\alpha(t)$ to be chosen for the next $T^{*}$ periods again is decreased while the propensities for the alternative incentive systems to be chosen are increased. Technically, the update of propensities $p\left(\alpha^{a}, t+1\right)$ follows the rule given by Brenner ([6], p. 907), i.e.,

$$
\begin{aligned}
p\left(\alpha^{a}, t+1\right)= & p\left(\alpha^{a}, t\right) \\
& +\left\{\begin{array}{cl}
\lambda \cdot\left(1-p\left(\alpha^{a}, t\right)\right) & \text { if } \alpha^{a}=\alpha(t) \wedge \tau(t)=1 \\
-\lambda \cdot p\left(\alpha^{a}, t\right) & \text { if } \alpha^{a}=\alpha(t) \wedge \tau(t)=-1 \\
-\lambda \cdot p\left(\alpha^{a}, t\right) & \text { if } \alpha^{a} \neq \alpha(t) \wedge \tau(t)=1 \\
\lambda \cdot \frac{p\left(\alpha^{a}, t\right) \cdot p(\alpha(t), t)}{1-p(\alpha(t), t)} & \text { if } \alpha^{a} \neq \alpha(t) \wedge \tau(t)=-1
\end{array} .\right.
\end{aligned}
$$

\section{Simulation Experiments and Parameter Settings}

The simulation experiments (for parameter settings see Table 2) presented in this paper are obtained for organizations facing a 12-dimensional binary decision problem (i.e., $N=12$ ). The decision problem is segmented into four distinct sub-problems of equal size where each sub-problem is delegated to one of four units (i.e., $M=4$ and $\left.N^{r}=3 \forall r\right)$.

\begin{tabular}{|c|c|}
\hline Parameter & Values/Types \\
\hline Observation period & $T=500$ \\
\hline Number of choices & $N=12$, i.e., $\mathbf{d}=\left(d_{1}, \ldots, d_{12}\right)$ \\
\hline $\begin{array}{l}\text { Number and scope } \\
\text { of departments }\end{array}$ & $\begin{array}{c}M=4: \mathbf{d}^{1}=\left(d_{1}, d_{2}, d_{3}\right), \mathbf{d}^{2}=\left(d_{4}, d_{5}, d_{6}\right) \\
\mathbf{d}^{3}=\left(d_{7}, d_{8}, d_{9}\right), \mathbf{d}^{4}=\left(d_{10}, d_{11}, d_{12}\right)\end{array}$ \\
\hline Interaction structures & $\begin{array}{l}\text { baseline scenarios: } \\
\quad \text { self-contained }\left(K=2, K^{*}=0\right) \\
\quad \text { full interdependent }\left(K=11, K^{*}=9\right) \\
\text { sensitivity analyses: eight intermediate levels } \\
\quad \text { from }\left(K=3, K^{*}=1\right) \text { to }\left(K=10, K^{*}=8\right)\end{array}$ \\
\hline $\begin{array}{l}\text { Alternative incentive } \\
\text { structures }\end{array}$ & $A=\{0,0.25,0.5,0.75,1\}$ \\
\hline $\begin{array}{l}\text { Precision of } \\
\qquad \text { ex-ante evaluation }\end{array}$ & $\begin{array}{l}\text { units: } \sigma^{r \text {,own }}=0.05 \\
\text { and } \sigma^{r \text {,res }}=0.2 \\
\text { headquarters: } \sigma^{\text {head }}=0.125\end{array}$ \\
\hline Modes of coordination & $\begin{array}{l}\text { baseline scenarios and first sensitivity analysis: } \\
\text { "decentralized" } \\
\text { second sensitivity analysis: } \\
\text { "sequential" } \\
\text { "horizontal veto" } \\
\text { "proposal" }\end{array}$ \\
\hline Interval of learning & $T^{*}=20$ \\
\hline Aspiration level & $v=0$ \\
\hline Learning strength & $\lambda=0.5$ \\
\hline
\end{tabular}

Table 2. Parameter settings. 
In the simulation experiments, after a fitness landscape is generated, the initial configuration $\alpha^{a} \in A$ of the incentive system is determined randomly out of five options (i.e., $|A|=5$ ) where each configuration of incentive systems has the same initial probability $\frac{1}{|A|}$.

The organizations are "thrown" randomly somewhere in the performance landscape and observed for 500 periods while searching for higher levels of performance and - with respect to this paper's research focus - in each $T^{*}$ th period, updating probabilities and, eventually, altering the incentive system. In particular, the organizations can switch between five levels of $\alpha$ in Eq. (3) (i.e., $A=\{0,0.25,0.5,0.75,1\})$ representing a range from incentivizing departmental performance only to rewarding firm performance with three intermediate levels.

To be clear and concise, a factorial design of the simulation experiments could help to find a way through the vast space of parameter settings [27]. With respect to the interaction structures (as given by parameters $N, K$ and $K^{*}$ ), this appears to be of particular relevance. ${ }^{c}$ Hence, first, simulation experiments are conducted for two, in a way extreme, baseline scenarios of intra-organizational complexity (see Figs. 1(a) and 1(c)):

In the "self contained" case intra-unit interactions among decisions are maximal intense while no cross-unit interactions $K^{*}$ exist (i.e., $K^{*}=0$ ). Hence, in this structure, it is possible to decompose the decision problem into disjoint partial problems, and each of these is delegated to a distinct business unit. This combination of decisional structure and delegation corresponds to a "self-contained" organization structure [16] and comes close to a pooled interdependence [29, 38]. These structures require rather limited coordination across the units and they are particularly feasible for firms pursuing strategies of geographical diversification or which create their units according to products in terms of product divisions.

In contrast, the interaction structure depicted in Fig. 1(c) could represent an organization with functional specialization with its typical high level of interrelations between units and, in consequence, high coordination need. This situation comes closest to reciprocal interdependence according to Thompsons classification of interdependencies in organizations [29, 38]. Hence, in this situation, decisional interdependence is raised to a maximum and, in particular, the cross-unit interference is raised to a maximum since all decisions affect the performance contributions of all other decisions and, thus, even cross-unit interactions are maximal (i.e., $K^{*}=9$ ). In these baseline scenarios, the organizations employ the "decentralized" mode of coordination, and, thus, are most closely related to assumptions about coordination as usually captured in related models based on principal-agent theory as indicated in

\footnotetext{
${ }^{\mathrm{c}}$ With $N=12$ decisions, as in the experiments introduced in this paper, an interaction matrix has 144 entries, of which those on the main diagonal are always set to $x$ (see Fig. 1). Hence, 132 other elements remain, each of which could be filled or not, and - since the level of $K$ does not necessarily need to be the same for every single decision $i-$, with $N=12$ in sum $2^{132}=5.44452 \cdot 10^{39}$ different interaction structures are possible. For a further discussion of different interaction structures, see [32].
} 


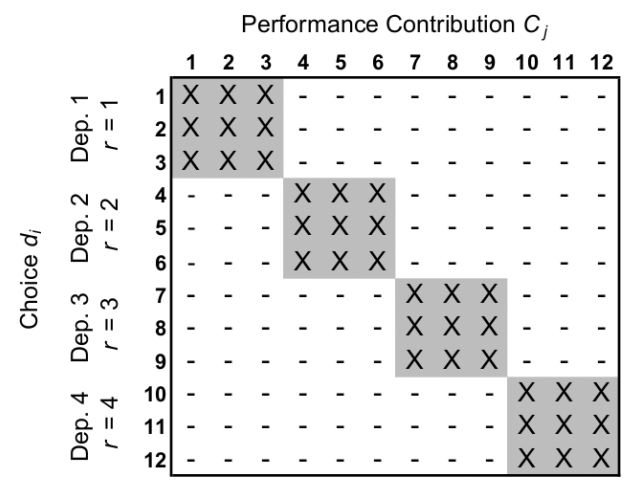

(a) Low complexity $\left(K=2, K^{*}=0\right)$ : self contained structure - no cross-unit interactions.

Performance Contribution $C_{j}$

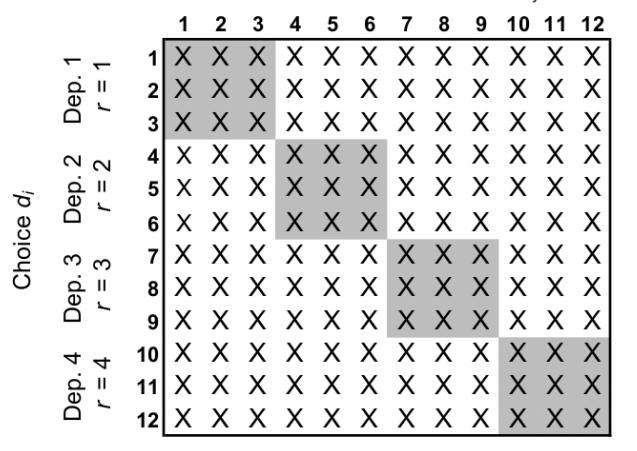

Notes:

Scope of primary control of department $r$

$X \quad$ Choice $i$ affects performance contribution $j$

- $\quad$ Choice $i$ does not affect performance contribution $j$ (b) Medium complexity $\left(K=5, K^{*}=3\right)$ : examplary intermediate structure - medium level of cross-unit interactions.

(c) High complexity $\left(K=11, K^{*}=9\right)$ : full

interdependent structure - maximal cross-unit.

Fig. 1. Decisional interaction structures and assignment of decisions to departments: (a) self-contained and (c) full interdependent structure as captured in the baseline scenarios of the simulation experiments and an example for an intermediate structure (b) as studied in the sensitivity analyses.

the introduction (Sec. 1). The results obtained for the baseline scenarios are presented in Sec. 4.1.

Second, for the decentralized mode of coordination, the paper presents a sensitivity analysis (see Sec. 4.2) which comprises all intermediate levels of intra-organizational complexity, i.e., for all level of $0<K^{*}<9$ where, for the sake of simplicity, it is assumed that the level of $K^{*}$ is the same for each performance contribution $C_{i}$ : For example, Fig. 1(b) depicts an organization with $K^{*}=3$.

Third, the simulation experiments are conducted for the other modes of coordination introduced in Sec. 2.4, i.e., "sequential", "horizontal veto" and "proposal". The aim of these experiments is to get some indication on potential interactions between the mode of coordination and the incentive systems emerging. These 
experiments are conducted for all levels of cross-unit interactions (i.e., ranging from $K^{*}=0$ to $K^{*}=9$ ) and related results are presented in Sec. 4.3.

\section{Results and Discussion}

\subsection{Baseline scenarios with "decentralized" coordination}

This study seeks to investigate which incentive systems (captured by different levels of $\alpha$ ) emerge under different conditions of intra-firm complexity and modes of coordination. As a starting point, in the baseline scenarios, two extreme levels of infrafirm complexity are analyzed for the "decentralized" mode of coordination which, in fact, does not provide any coordination beyond those coordinative effects resulting from the incentives given: Each unit head is allowed to implement that option that he/she prefers most - according to the incentive system. While, in the beginning of an adaptive search, each level of $\alpha$ has the same probability to be chosen, in the course of the adaptive search, the propensities and, with this, the frequencies of the incentive systems may change.

Figure 2 displays, for the incentive systems $\alpha$ implemented in the last period $t=500$, the final performance (i.e., $V_{t=500}$ according to Eq. (2)), ${ }^{\mathrm{d}}$ and, on the secondary vertical axis, the frequency of how often the global maximum is found in the final period as well as the relative frequency of the respective incentive system. Figure 3 displays the relative frequencies of the different incentive systems in the course of the adaptive walks due to learning-based adjustments. Table 3 reports on the significance of mean differences of final performance achieved in adaptive walks with different incentive systems (i.e., walks are grouped by the incentive structure employed in the final period) according to Welch's method [23, 41].

The results suggest that for different levels of cross-unit interactions different incentive systems emerge: Without cross-unit interactions $\left(K^{*}=0\right)$ rewarding departmental performance only (i.e., $\alpha=0$ ) clearly predominates with about $72 \%$ of relative frequency; for the maximum level of intra-firm complexity (i.e., $K=11$ and $K^{*}=9$ ) rewarding merely departmental performance is least often implemented (in about $12 \%$ of the 2500 adaptive walks) while, notwithstanding, no clear predominance among the higher levels of $\alpha$ appears.

For situations without cross-unit interactions, these results appear reasonable since then, basically, there is no need for taking effects of departmental choices on the rest of the organization into account (with $\alpha>0$ these effects would be considered). In contrast, with intense cross-departmental interactions positive or negative spillover effects are likely to occur which, depending on $\alpha$, are considered "more or less" in managerial decision-making.

These results, in principle, are in line with a relevant study by Bushman et al. [8] which shows that the use of aggregate performance measures is an increasing

\footnotetext{
$\mathrm{d}$ The final performance $V_{t=500}$ is given in relation to the global maximum of the respective performance landscapes since, otherwise, the results could not be compared across performance landscapes.
} 


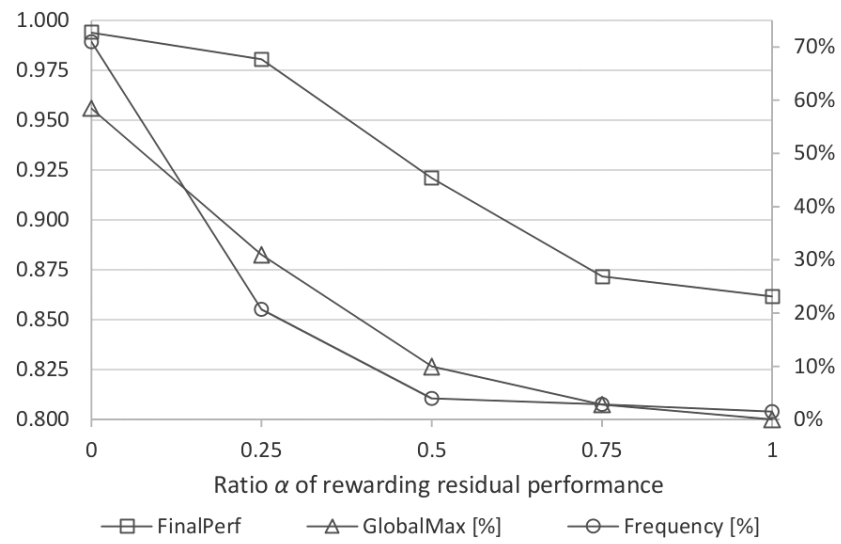

(a) Low complexity $\left(K=2, K^{*}=0\right)$ : no cross-unit interactions.

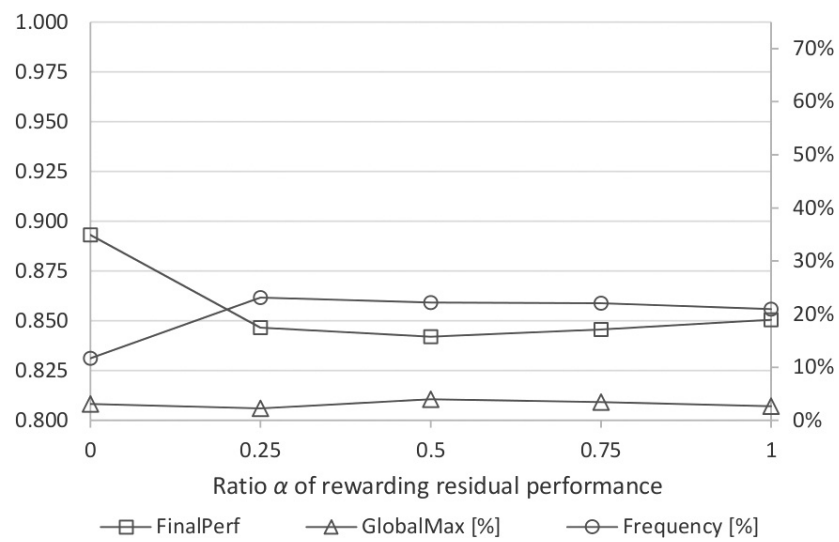

(b) High complexity $\left(K=11, K^{*}=9\right)$ : maximum cross-unit interactions.

Fig. 2. Condensed results of adaptive walks of the baseline scenarios grouped according to the incentive system $\alpha$ implemented in the last period of the adaptive walks.

Notes: Confidence intervals of final performance range from 0.0010 to 0.0037 for low and from 0.0115 to 0.0130 for high complexity of interactions - each at a confidence level of 0.999 . Results for 2500 adaptive walks: 250 distinct fitness landscapes, with 10 adaptive walks on each. For further parameter settings, see Table 2.

function of intra-firm interdependencies ([8], p. 101) — though with different methodological approaches than applied in this paper: The authors employ a closedform analysis based on a principal-agent model as well as an empirical study based on a sample of 246 firms which participated in a survey on compensation plans. To empirically measure the level of intra-firm interdependencies, Bushman et al. use firm-wide characteristics like diversification or intra-firm sales where the latter is regarded as a proxy for intra-company interdependencies. Hence, the results of our 


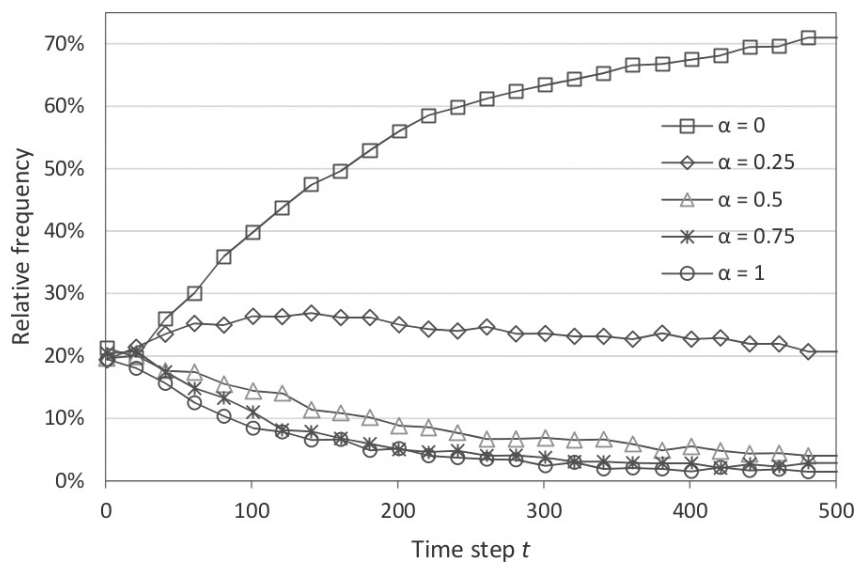

(a) Low complexity $\left(K=2, K^{*}=0\right)$ : no cross-unit interactions.

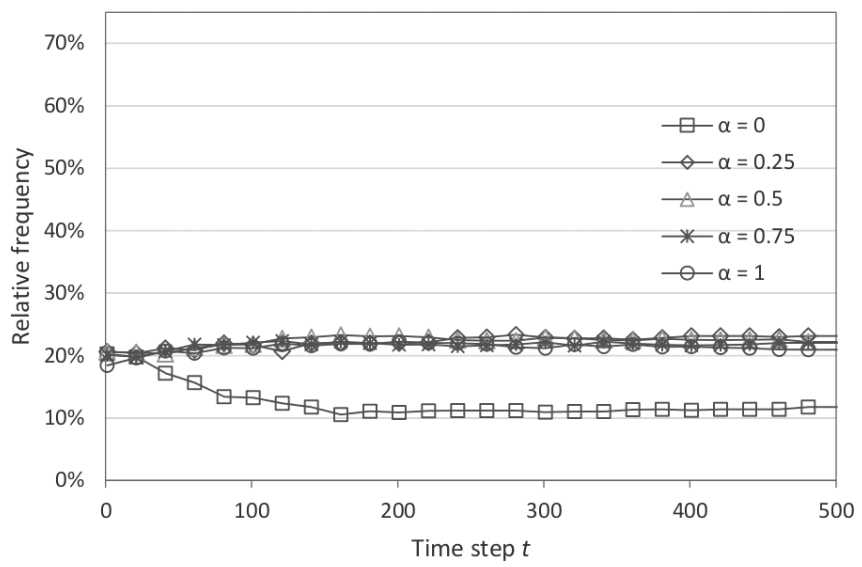

(b) High complexity $\left(K=11, K^{*}=9\right)$ : maximum cross-unit interactions.

Fig. 3. Relative frequencies of different incentive systems within the course of the adaptive walks.

Notes: Results for 2500 adaptive walks: 250 distinct fitness landscapes, with 10 adaptive walks on each. For further parameter settings, see Table 2 .

simulation experiments, so far, underline the robustness of the key message of Bushman et al.'s theoretical and empirical study. ${ }^{\mathrm{e}}$

However, results displayed in Figs. 2(b) and 3(b) suggest that, with maximum cross-departmental interactions, a maximum emphasis on residual performance (i.e., $\alpha=1$ ) does neither show the highest final performance nor does it evolve most often. Rather it appears, that — as far as the residual performance (Eq. (3)) is rewarded at

e However, it should be mentioned that in their theoretical part Bushman et al. (implicitly) assume the decentralized mode of coordination and that the empirical part of their study does not control for the mode of coordination [40]. 
Table 3. Individual $99.9 \%$ confidence intervals for all pairwise comparisons of means of final performance $V_{t=500}$ of baseline scenarios obtained for different incentive systems as implemented in $t=500$; mean differences and half-lengths denoted.

\begin{tabular}{|c|c|c|c|c|}
\hline & $\alpha=0.25$ & $\alpha=0.5$ & $\alpha=0.75$ & $\alpha=1$ \\
\hline \multicolumn{5}{|c|}{ Low complexity $\left(K=2, K^{*}=0\right)$ : no cross-unit interactions } \\
\hline $\begin{array}{l}\alpha=0 \\
\alpha=0.25 \\
\alpha=0.5 \\
\alpha=0.75\end{array}$ & $0.0133 \pm 0.0028^{*}$ & $\begin{array}{l}0.0729 \pm 0.0186^{*} \\
0.0596 \pm 0.0188^{*}\end{array}$ & $\begin{array}{l}0.1221 \pm 0.0246^{*} \\
0.1088 \pm 0.0247^{*} \\
0.0492 \pm 0.0286^{*}\end{array}$ & $\begin{aligned} 0.1321 & \pm 0.0308^{*} \\
0.1188 & \pm 0.0309^{*} \\
0.0592 & \pm 0.0362^{*} \\
0.01 & \pm 0.0386\end{aligned}$ \\
\hline \multicolumn{5}{|c|}{ High complexity $\left(K=11, K^{*}=9\right)$ : maximum cross-unit interactions } \\
\hline $\begin{array}{l}\alpha=0 \\
\alpha=0.25 \\
\alpha=0.5 \\
\alpha=0.75\end{array}$ & $0.0466 \pm 0.0149^{*}$ & $\begin{array}{l}0.0511 \pm 0.0155^{*} \\
0.0045 \pm 0.0136\end{array}$ & $\begin{aligned} 0.0476 & \pm 0.0156^{*} \\
0.001 & \pm 0.0136 \\
-0.0036 & \pm 0.0143\end{aligned}$ & $\begin{aligned} 0.0426 & \pm 0.0156^{*} \\
-0.004 & \pm 0.0137 \\
-0.0085 & \pm 0.0143 \\
-0.0049 & \pm 0.0144\end{aligned}$ \\
\hline
\end{tabular}

Notes: * indicates a significant difference.

all, i.e., as far as $\alpha>0$, results are fairly insensitive to the level of $\alpha$. Of course, this is to be analyzed in more detail, especially to figure out whether certain findings of, in particular, the closed-form model of Bushman et al. [8] might be relativized for settings with less gifted agents. This might be of particular interest since Bushman et al., with respect to the explanatory variables, due to the unavailability of appropriate data, do not empirically examine those parts of their theoretical findings which are related to the information quality (noise) of the performance measures. The sensitivity analysis presented subsequently may be regarded as a step to more explicitly incorporate the effects of imperfect information in the analysis.

\subsection{Sensitivity analysis for the decentralized mode of coordination: The role of informational imperfections}

The first sensitivity analysis aims at analyzing more into detail the effects of intrafirm complexity in the decentralized mode of coordination. Hence, simulation experiments for all levels of cross-unit interactions from $K^{*}=0$ (i.e., the self-contained structure in Fig. 1(a)) up to a maximum level of intra-firm complexity of $K^{*}=9$ (the full interdependent structure in Fig. 1(c)) were conducted - employing the "decentralized" mode of coordination. The upper left part of Fig. 4 reports on the final performance $V_{t=500}$ grouped by those incentive schemes $\alpha$ implemented in the last period of observation. The upper right part shows the relative frequency of each incentive scheme $\alpha$ implemented in $t=500$ for a given level of intra-firm complexity.

The results provide some mixed findings: In general, it appears that with increasing intra-firm complexity a shift from rewarding merely departmental performance towards rewarding firm performance can be observed which is in line with the aforementioned closed-form analysis and empirical study of Bushman et al. [8]. However, results do not suggest a monotonous increase of $\alpha$ with increasing level of $K^{*}$. Results rather indicate that, roughly speaking, a fairly low emphasis on 

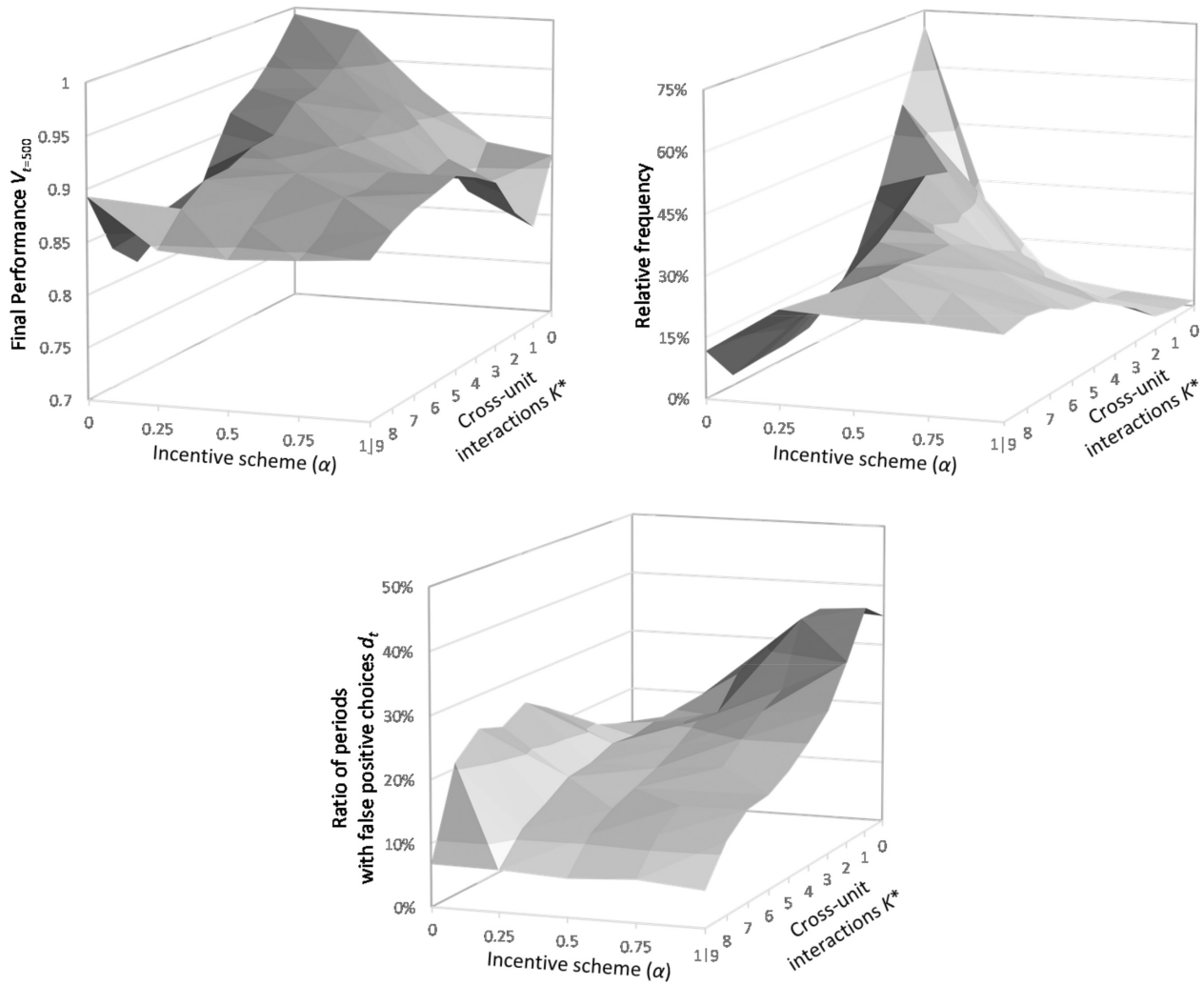

Fig. 4. Final performance (upper left), frequency of incentive systems (upper right) and ratio of false positive choices (down) grouped by incentive systems implemented in the last period of the adaptive walks for different levels of intra-firm complexity with "decentralized" coordination.

Notes: For each level of intra-firm complexity $K^{*}=(0, \ldots, 9), 2500$ adaptive walks are simulated: 250 distinct fitness landscapes, with 10 adaptive walks on each. For further parameter settings, see Table 2.

residual performance (i.e., $\left.\alpha^{r}=0.25\right)$ predominates for low levels of complexity (i.e., $K^{*} \in\{1,2,3,4\}$ ) and even for relatively high levels of intra-firm complexity (i.e., $K^{*} \geq 5$ ) medium emphasis on residual performance is slightly predominant.

Hence, an interesting question is what might cause these results. A closer analysis of the simulation experiments reveals that presumably the diversity of search and, in particular, false positive alterations are of relevance (lower part of Fig. 4): False positive alterations mean that the organization makes choices of $\mathbf{d}_{t}$ which lead to a decrease in performance $V_{t}$ compared to the performance achieved in the previous period, i.e., $V_{t-1}$. Comparing the upper left and upper right part to the lower part of Fig. 4, suggests that, in tendency, those configurations which come along with high levels of false positive alterations lead to lower performances and emerge less often for a given level of $K^{*}$, and vice versa. 
For a closer analysis, it appears helpful to recall the sources of informational imperfections in decision-making which are explicitly captured in the simulation model:

(1) At each time step $t$ head of department $r$ knows three alternatives of the partial decision $d^{r}$ (and not the entire solution space).

(2) Head of department $r$ cannot perfectly estimate the contribution of a certain option on the "own", i.e., the departmental, performance $\left(\sigma^{r, \text { own }}\right)$

(3) Head of department $r$ has rather noisy information about the contribution of a certain option to the "residual" performance $\left(\sigma^{r, \text { res }}\right)$

(4) Head of department $r$ does not know in advance which choices the other units $q \neq r$ will opt for.

(5) The headquarters cannot perfectly ex ante evaluate the performance of an option $\left(\sigma^{\text {head }}\right)$.

In the decentralized mode of coordination, item (5), obviously, is not relevant (see Sec. 2.4 and Table 1). In contrast, items (1) and (2), obviously, are relevant in the decentralized mode and, in particular, are effective regardless of $\alpha$, i.e., of variations of rewarding residual performance (see Eqs. (3) and (6)). However, in the decentralized mode interactions of intra-firm complexity and level of $\alpha$ with items (3) and (4) occur: With increasing $\alpha$, the relatively noisy information on residual performance is reflected in the departmental ex ante evaluation of options - and these errors are in tendency the higher the lower intra-firm complexity $K^{*}$. With lower $K^{*}$ more "phantom-like" interactions (i.e., spillover effects which do not exist) are considered by the department heads. Moreover, unknown current choices of the other units (item (4)) are the more relevant the higher the level of complexity.

Hence, the incentive system itself could be regarded as a source of additional informational imperfections as well as an "immunization" against items (3) and (4): With $\alpha=0$, the unit heads ignore the rest of the organization and, thus, items (3) and (4) do not interfere in decision-making. This "ignorance" appears appropriate in case of minimum level of intra-firm complexity $K^{*}=0$ since then there are no spillover effects to take into account. In this sense, it is appropriate when the incentive system "prevents" units from considering spillover effects which do not exist (e.g., [35]) — and which may lead to high ratios of false positive movements as can be seen for $K^{*}=0$ and $\alpha \geq 0.5$ in the lower plot of Fig. 4. However, with increasing $K^{*}$ rewarding merely unit performance becomes a source of misjudgment by its own.

Moreover, informational imperfections obviously may lead to misjudgments but it is well known that they also can have positive effects (e.g., [24, 39]): Inducing false positive decisions may lead to performance losses in short term; however, it provides the chance to leave a current area in the performance landscape and, thus, of reducing the peril of sticking to local optima. These beneficial effects occur particularly in case of highly rugged landscapes (e.g., for $K^{*}=9$ ) which are rather prone to inertia. Obviously, these potentially beneficial effects of informational imperfections 
are relevant only if agents do not know the entire solution space in advance (item 1) — otherwise decision-makers would just implement the optimal solution.

Hence, these considerations suggest that with the incentives given subtle and partially opposing effects in respect of informational imperfections are induced which may explain the results displayed in Fig. 4.

\subsection{Analysis for other modes of coordination}

So far, the analysis of results was related to the "decentralized" mode of coordination which incorporates the highest autonomy of departmental decision-makers. However, in contrast to the other modes of coordination captured in the simulation model, the decentralized mode does not make use of any communication of preferences or of a second evaluation of preferences — which could both interfere with informational imperfections. Hence, an interesting question is if, with the other modes of coordination, the emergence of incentive schemes and, of course, the levels of performance achieved are affected. In order to provide some guidance for the subsequent analysis, Table 4 summarizes the informational imperfections (according to the list presented in Sec. 4.2) that are effective in the different modes of coordination.

\subsection{1. "Sequential" mode of coordination}

Figure 5 shows the results obtained for the "sequential" mode of coordination corresponding to the plots in Fig. 4. With respect to the relative frequencies, the results suggest that for low intra-firm complexity rewarding unit performance is employed predominantly whereas with higher levels of intra-firm complexity putting more

Table 4. Informational imperfections effective in different modes of coordination.

Informational imperfections Decentralized mode Sequential mode Horizontal mode Proposal mode

\begin{tabular}{|c|c|c|c|c|}
\hline $\begin{array}{l}\text { (1) Limited knowledge } \\
\text { of solution space }\end{array}$ & yes & yes & yes & yes \\
\hline $\begin{array}{l}\text { (2) Units' imprecise } \\
\text { ex ante evaluation } \\
\text { of options' impact } \\
\text { on "own" performance }\end{array}$ & yes & yes & yes & yes \\
\hline $\begin{array}{l}\text { (3) Units' imprecise } \\
\text { ex ante evaluation of } \\
\text { options' spillover effects } \\
\text { on residual performance }\end{array}$ & $\begin{array}{l}\text { yes, if } \\
\alpha>0\end{array}$ & $\begin{array}{l}\text { yes, if } \\
\alpha>0\end{array}$ & $\begin{array}{l}\text { yes, if } \\
\alpha>0\end{array}$ & $\begin{array}{l}\text { yes, if } \\
\alpha>0\end{array}$ \\
\hline $\begin{array}{l}\text { (4) Units' imperfect } \\
\text { knowledge of other } \\
\text { units' preferences/ } \\
\text { choices }\end{array}$ & yes & $\begin{array}{l}\text { first unit: yes; } \\
\text { "mid" units: } \\
\text { partially; } \\
\text { last unit: no }\end{array}$ & $\begin{array}{l}\text { when forming } \\
\text { preferences: yes; } \\
\text { when deciding } \\
\text { about veto: no }\end{array}$ & yes \\
\hline $\begin{array}{l}\text { (5) Headquarters' } \\
\text { imprecise ex ante } \\
\text { evaluation of options }\end{array}$ & no & no & no & yes \\
\hline
\end{tabular}



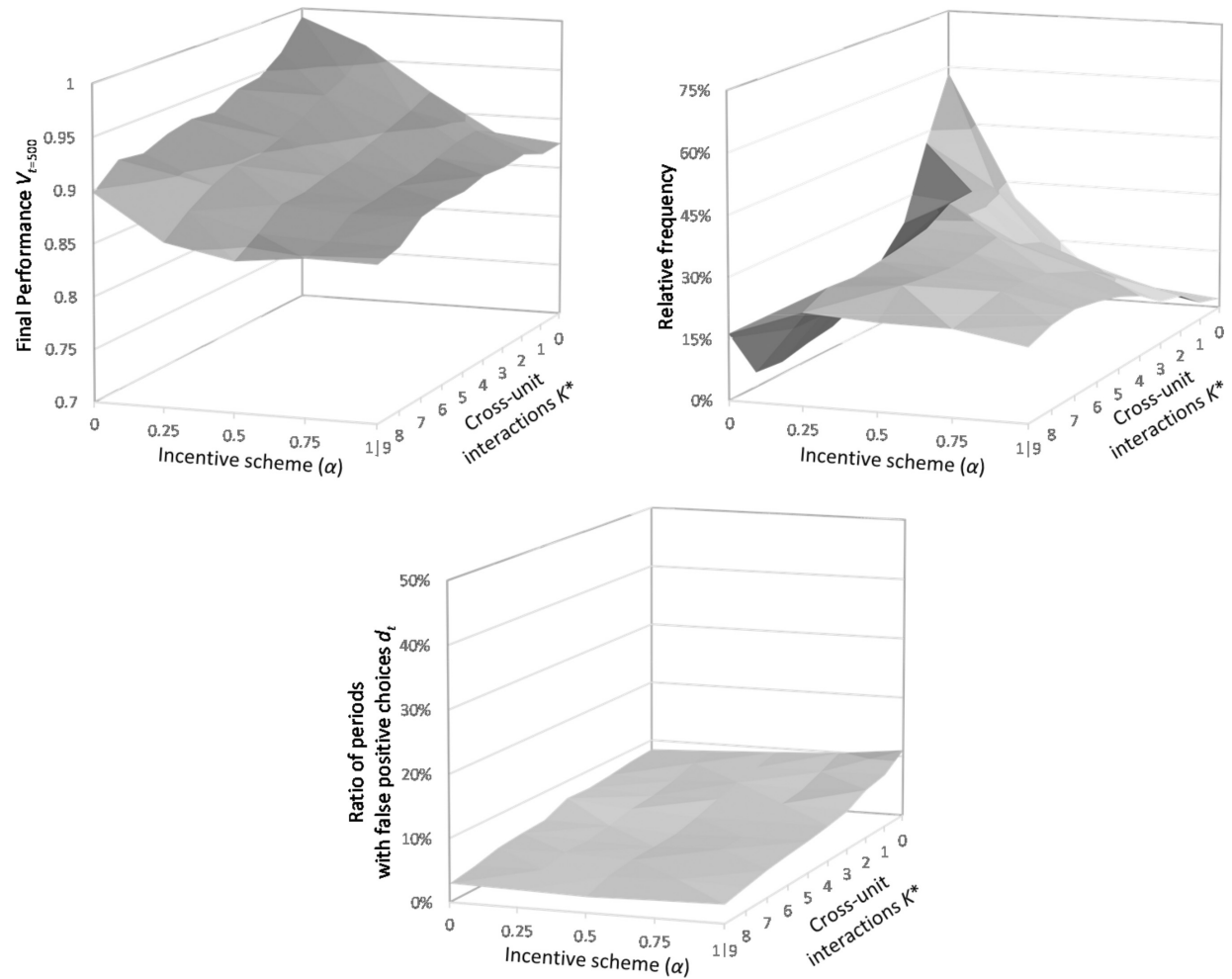

Fig. 5. Final performance (upper left), frequency of incentive systems (upper right) and ratio of false positive choices (down) grouped by incentive systems implemented in the last period of the adaptive walks for different levels of intra-firm complexity with "sequential" coordination.

Notes: See notes to Fig. 4.

emphasis on firm performance (i.e., $\alpha>0$ ) occurs more frequently. These findings correspond, in principle, to those obtained for the "decentralized" mode and with this, results are also in line with the empirical study of Bushman et al. [8] as well as with their closed-form analysis which employs (implicitly) the decentralized mode and with more gifted agents than captured here.

However, results of the sequential mode show some aspects which are worth to be discussed more into detail. First, in comparison against the decentralized mode, the final performance achieved with sequential decision-making appears less sensitive to the incentive system and to the level of intra-firm complexity (ranging from 0.7982 to 0.9938 in the decentralized mode and from 0.8426 to 0.9914 in the sequential mode). Second, the ratio of false positive decisions is remarkably lower: While in the decentralized mode $5 \%$ up to $38 \%$ of alterations are in favor of false positive options, this is the case in only $2.5 \%$ up to $11 \%$ of choices in the sequential mode.

Hence, an interesting question is what causes these "flattening" effects of sequential decision-making. It appears reasonable that the knowledge of the choices of 
the "preceding" units and the re-evaluation of the own options in face of this knowledge is the key for these effects. In particular, with sequential decision-making, one source of imperfect information on the units' site of decentralized mode is mitigated, i.e., that unit head $r$ does not know in advance which choices the other units $q \neq r$ will opt for (item 4 in Table 4 ): Unit 1 has to make its choice without knowing what the other units will do; but unit 2 knows what unit 1 opted for and can reevaluate the own options accordingly - though assuming that units $r \geq 3$ will stay with the status quo; unit 3 gets knowledge of choices of units 1 and 2, re-evaluates its options and so forth. Hence, with sequential decision-making, the errors made due to imperfect knowledge about the other units' choices are reduced — the more the later in the sequence, a certain unit is located.

Therefore, in the sequential mode even with low or zero emphasis $\alpha$ on residual performance, spillover effects on the "own" performance are considered partially: If a unit $r>1$ re-considers its preferences, now knowing the choices of the preceding units, then unit $r$ after all can adjust to the spillover effects of the preceding choices on the own scope of competencies - though afflicted with error $\sigma^{\text {r,own }}$. With higher levels of $\alpha$, this beneficial effect of sequential decision-making is overlaid by higher levels of errors $\sigma^{r \text {,res }}$ related to "residual" performance (item 3 in Table 4) and this effect is the more relevant the higher the level of intra-firm complexity which may explain the shape of the figure for final performance in Fig. 5.

\subsection{2. "Horizontal veto" mode of coordination}

Results obtained for the "horizontal veto" mode of coordination are displayed in Fig. 6. The results suggest that under the regime of the "horizontal veto" mode, the final performance achieved is fairly insensitive to the incentive system — while it is not to the level of intra-firm complexity. This might be regarded as an indication that the mode of coordination may "overrule" the effects of the incentive system. Moreover, the level of performance achieved - especially in case of higher levels of intrafirm complexity is remarkably below that level achieved under the regime of the decentralized as well as the sequential mode. Furthermore, with respect to the relative frequency of the reward structures, the results suggest that for low levels of intra-firm complexity, a rather clear predominance $(29 \%)$ of rewarding merely unit performance occurs. With increasing intra-firm complexity, the differences in frequencies diminish.

Of course, an interesting question is what may cause these results, especially with respect to final performance. I argue, that, in the veto mode of coordination, informational imperfections lead to rather "overcautious" decision-making and, in consequence, to inertia:

In the horizontal veto mode, the units inform each other about their preferences and each unit evaluates the vector of all first (second) preferences - including the own first (second) preference - according to the incentives $\alpha$ given: When a unit head evaluates the configuration composed of the first (second) preferences of all 

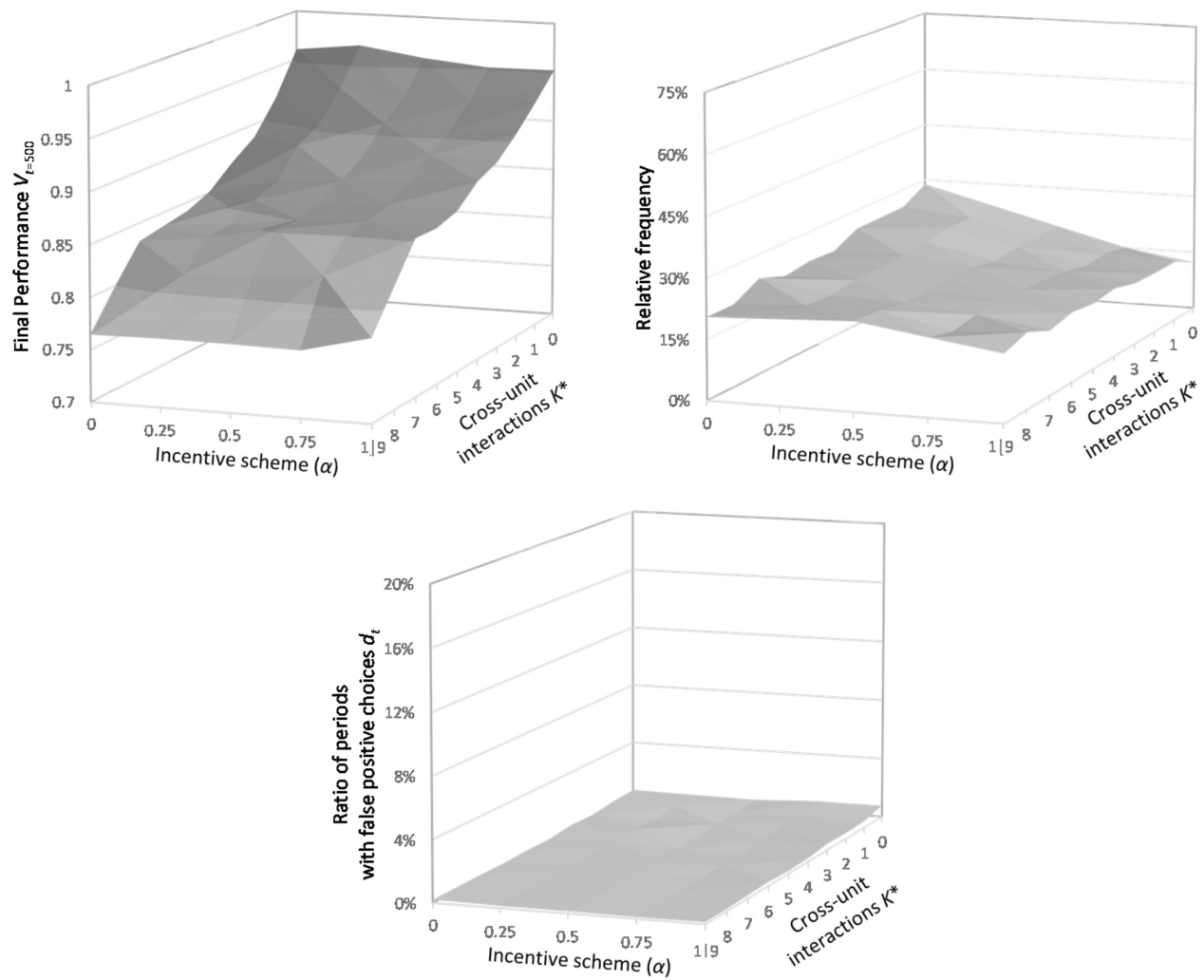

Fig. 6. Final performance (upper left), frequency of incentive systems (upper right) and ratio of false positive choices (down) grouped by incentive systems implemented in the last period of the adaptive walks for different levels of intra-firm complexity with "horizontal veto" mode of coordination.

Notes: See notes to Fig. 4.

units with respect to consequences on the own salary, then the errors $\sigma^{r, \text { own }}$ related to the departmental performance (item 2) and - depending on incentives $\alpha$ - errors $\sigma^{r, \text { res }}$ related to the residual performance (item 3 ) are effective.

Moreover, the imperfect knowledge of the other units' $q \neq r$ preferences (item 4 in Table 4) in a way continues to affect decision-making - even after the units have informed each other: Obviously, in this mode, the first formation of a unit's $r$ first (second) preferences is affected by imperfect knowledge about the other units' $q \neq r$ choices. After the units have informed each other about their preferences, each unit reassesses its preferences as a part of the entire configuration resulting from all units' first (second) preferences. However, in contrast to the sequential mode, a unit $r$ does not re-order its list of preferences after it gets knowledge of the other units' preferences. Instead, each unit decides about vetoing: recall that the vector composed of the once firmed first (or second) preferences is implemented only if no unit is worse off than with keeping the status quo - otherwise a unit which is worse off would veto. 
Hence, in this sense the very low ratio of periods with false positive alterations of about 0.1 up to $0.8 \%$ appears reasonable (lower part of Fig. 6).

However, the downside of preventing false positive evaluations are false negative evaluations: Whenever one of the $M$ units falsely evaluates the composite vector of first (second) preferences as negative - due to imperfections (2) and (3) in Table 4 - , this unit will veto and, thus, no alteration will take place. ${ }^{f}$ With a shift to firm performance, i.e., higher levels of $\alpha$, the peril of false negative evaluations increases, since then the rather imprecise knowledge on the rest of the organization (item 3 in Table 4) affects the units' evaluations. Adaptive search processes on performance landscapes with higher levels of complexity are more prone to inertia, and, thus, may be even more affected by inertia induced by this particular mode of coordination (e.g., [36]). This may explain the rather low final performance for levels of high intra-firm complexity — particularly in comparison to the levels achieved with decentralized and sequential coordination.

\subsection{3. "Proposal" mode of coordination}

Results for the proposal mode (Fig. 7) suggest that for lower levels of intra-firm complexity merely rewarding departmental performance leads to higher levels of performance than rewarding residual performance too; correspondingly incentive structures with $\alpha=0$ clearly predominate, i.e., evolve most often. For higher levels of intra-firm complexity, performance differences between the different levels of $\alpha$ diminish and no predominance is apparent. In general, the findings (again) correspond to theoretical findings based on principal-agent theory and related empirical results [8], though some aspects may deserve some further considerations.

First of all, it is worth mentioning that this is the only mode of coordination where the headquarters intervenes in decision-making and, with this, the rather coarse knowledge of the headquarters (i.e., $\sigma^{\text {head }}$ ) affects $e x$ ante evaluations of options (item 5 in Table 4). Hence, in the proposal mode, all of the informational imperfections explicitly captured in the simulation model are effective.

With the headquarters being involved and whatever incentives given, the units' most preferred options are evaluated a second time and, in particular, with respect to firm performance. In this sense, it appears reasonable that the final performance does not vary that much with the incentive system $\alpha$ for a given level of intra-firm complexity; moreover, the final performances achieved for high levels of complexity are the best compared to all other coordination modes. Hence, apparently, the headquarters' contribution appears to be most valuable when intra-organizational complexity and, hence, coordination need is rather high.

With respect to false positive movements (lower part in Fig. 7), the proposal mode shows rather low ratios - especially, if compared to the decentralized mode. These

f This is broadly confirmed by the ratio of periods with alterations - which, in the "horizontal veto" mode, in case, for example, of maximum intra-firm complexity $\left(K^{*}=11\right)$ ranges at $0.6 \%$ of the periods; for the same level of complexity it ranges around $12.5 \%$ in the decentralized and around $6 \%$ in the sequential mode. 

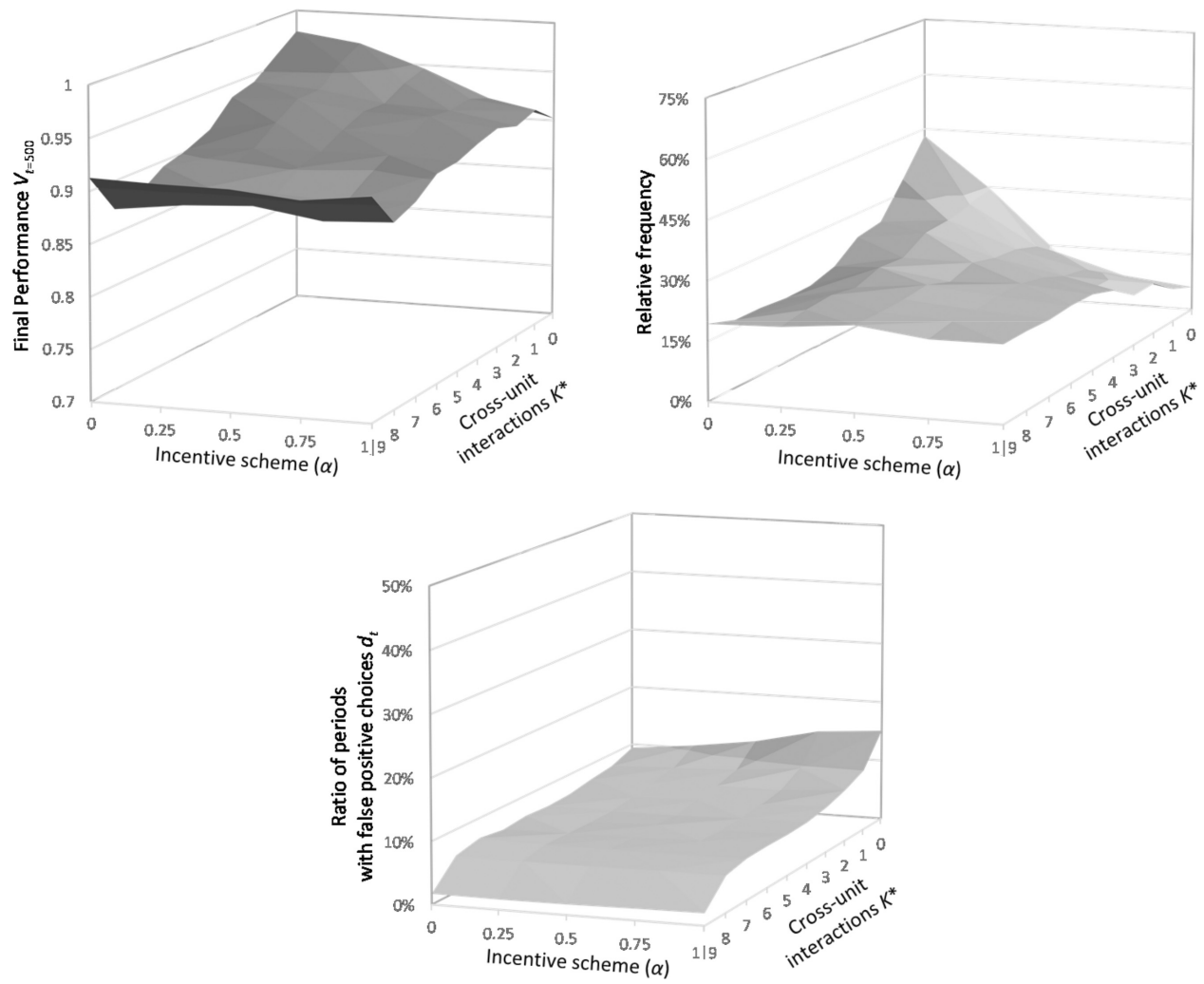

Fig. 7. Final performance (upper left), frequency of incentive systems (upper right) and ratio of false positive choices (down) grouped by incentive systems implemented in the last period of the adaptive walks for different levels of intra-firm complexity with the proposal mode of coordination.

Notes: See notes to Fig. 4.

findings broadly correspond to the seminal work of Sah and Stiglitz [34] (employing a closed form model) which indicates that with "polyarchies" in the terminology of Sah and Stiglitz (close to decentralized coordination introduced in this paper) more false positive options are accepted; in contrast, with "hierarchies" in terms of Sah and Stiglitz — i.e., the headquarters making the final choice — an option has to pass a second instance to be accepted. Hence, the peril of false positive choices is reduced.

\section{Conclusion}

This study investigates incentive systems as evolving over time through learning under different conditions of intra-firm complexity and for different modes of coordination. Particular focus is put on informational imperfections which go beyond that level of bounded rationality that is typically captured in closed-form models based on principal-agent theory. 
In a rather broad sense, the results of this simulation study are in line with findings of closed-form models confirmed by empirical results suggesting that with low intra-firm complexity rewarding mainly departmental performance is more appropriate whereas, with higher levels of intra-firm complexity, a shift towards rewarding firm performance becomes appropriate. However, this finding is to be put into perspective for several aspects.

First, although the results obtained in this paper suggest that with higher levels of intra-firm complexity rewarding firm performance evolves more often, no clear predominance is apparent. The paper argues that this might be caused by the particular role, the incentive system plays in presence of informational imperfections: With more emphasis on firm performance, potential spillover effects of departmental decisions on the rest of the organization are considered - which appears appropriate for high levels of intra-firm complexity. At the same time, the potentially rather coarse knowledge of departments about effects of own decisions beyond the own scope of competencies is involved in decision-making. Hence, whether the incentive system generates (inappropriate) ignorance of spillover effects or serves as a kind of "shield" against too noisy information on spillover effects is, all else equal, subject to the level of intra-firm complexity.

Second, the results suggest that the mode of coordination, i.e., the way how preferences on the departmental site are aligned with each other, may considerably affect the emergence of the incentive structure. In particular, the "decentralized" mode of coordination (which corresponds most purely to related principal-agentmodels) leads to the most pronounced predominance of certain incentive structures. In contrast, the incentive system seems to be rather irrelevant with respect to performance achieved in case of the "horizontal veto" mode. A closer analysis, particularly based on the ratio of false positive decisions, reveals that the modes of coordination affect which informational imperfections interfere in decision-making.

In a more general sense, the findings obtained provide support for the idea that management controls — like the incentive system and the mode of coordination should be regarded and designed as a system, i.e., taking interactions among them into account, rather than as merely a collection of different control mechanisms.

However, this also calls for ways to evaluate the model and, in particular, the results obtained in this paper. Of course, an interesting approach is to conduct empirical research in order to find some indication on the hypothesized effects and interactions discussed in this paper. First of all, it is worth mentioning that, to a certain extent, the study of Bushman et al. [8] provides some empirical support for key findings of the simulation study proposed in this paper. However, the support is limited since some rather crucial aspects so far are not captured and, presumably, are hard to capture precisely in empirical studies at all: A key explanatory variable in the argumentation introduced (by Bushman et al. as here) are informational imperfections, and presumably, it requires, substantial further research to empirically determine the effective levels of informational imperfections in organizations to be able to control for in empirical studies. 
Another aspect to be subject of an (empirical) evaluation is the hypothesized emergence of incentive systems. Further research requires, at least, to capture two questions: First, longitudinal analyses are required to study the emergence of incentive systems and other control practices and, second, to investigate the interrelations among different control practices (see also [18]). In this respect, further simulation analyses as suggested in this paper might be of help for generating hypotheses to be tested empirically. For example, in the study presented in this paper, the coordination mode has been exogenously given; but, of course, it would be rather interesting to let organizations not only learn on the incentive system but on the coordination mode and observe which configurations of both control practices emerge under which conditions. This might help to generate hypotheses for further empirical research, and, in particular, to identify predominant configurations of management control practices [5] and their contextual factors.

Moreover, an obvious extension of this study would be to include further sources of informational imperfections which may result from communication: Three of the modes of coordination analyzed in this study employ communication of preferences among fellow units ("sequential", "horizontal veto") or the headquarters ("proposal"). Of course, there is no guarantee that communication is free from errors - may they be accidentally or deliberately. Hence, an interesting question is how robust the results obtained in this study are towards communication errors. Moreover, extending the study to further alternative reward structures (e.g., nonlinear schemes) or alternative learning modes (e.g., belief-based learning) could be of particular interest.

\section{Appendix A. List of Symbols}

Table A.1. List of Symbols.

\begin{tabular}{|c|c|}
\hline Symbols & Meaning \\
\hline$\alpha^{r}$ & $\begin{array}{l}\text { Ratio to which the performance achieved by departments other than } r \text {, } \\
\text { i.e., } P_{t}^{r, \text { res }} \text {, is reflected in value base for compensation } P_{t}^{r}\left(\mathbf{d}_{t}\right) \text { of department } \\
r \text { 's head }\end{array}$ \\
\hline$\alpha(t)$ & $\begin{array}{l}\text { Incentive system implemented in time step } t \text { with } \alpha^{r}=\alpha(t) \\
\qquad \forall r=(1, \ldots, M)\end{array}$ \\
\hline$\alpha^{a}$ & Possible option for the incentive system $\in A=\left\{\alpha^{1}, \ldots, \alpha^{a}, \ldots, \alpha^{|A|}\right\}$ \\
\hline$\lambda$ & Learning strength within reinforcement learning \\
\hline$\phi_{t}$ & $M$-dimensional configuration of incentives given to the $M$ units in $t$ \\
\hline$\sigma^{r, \text { own }}, \sigma^{r, \text { res }}$ & Standard deviations of errors $e^{r, \text { own }}$ and $e^{r \text {,res }}$, respectively \\
\hline$\sigma^{\text {head }}$ & Standard deviation of informational error made by the main office \\
\hline$\tau(t)$ & $\begin{array}{l}\text { Feedback within learning by reinforcement received from incentive system } \alpha^{a} \\
\quad \text { implemented in the last } T^{*} \text { periods }\end{array}$ \\
\hline$\omega$ & Pay-off of prior choice of the incentive system, i.e., of $\alpha(t)$ \\
\hline$a$ & Index for incentive systems \\
\hline$A$ & Set of alternative incentive systems captured by $\alpha^{a}$ \\
\hline$C_{i t}$ & Contribution of binary choice $i$ in time step $t$ to overall performance $V_{t}$ \\
\hline$d_{i t}$ & Binary choice $i$ in time step $t$, i.e., $d_{i t} \in\{0,1\}$ \\
\hline
\end{tabular}


Table A.1. (Continued)

\begin{tabular}{|c|c|}
\hline Symbols & Meaning \\
\hline $\mathbf{d}_{C}$ & $\begin{array}{l}N \text {-dimensional vector composed from units' options related to } \mathbf{d}_{t} \\
\text { According to the respective coordination mode }\end{array}$ \\
\hline $\mathbf{d}_{t}$ & $N$-dimensional vector of binary choices $d_{i t}$ in time step $t$ \\
\hline $\mathbf{d}_{t}^{r}$ & $\begin{array}{l}N^{r} \text {-dimensional vector of binary choices } d_{i t} \text { in time step } t \\
\text { which department } r \text { is responsible for }\end{array}$ \\
\hline $\mathbf{d}_{t-1}^{r *}$ & Status quo of department $r$ 's choices, i.e., choices made in period $t-1$ \\
\hline $\mathbf{d}_{t}^{r, a 1}, \mathbf{d}_{t}^{r, a 2}$ & $\begin{array}{l}\text { Alternative configurations of department } r \text { 's choices where } 1 \text { or } 2 \text { choices, } \\
\text { respectively, are flipped compared to the status quo } \mathbf{d}_{t-1}^{r *}\end{array}$ \\
\hline $\mathbf{d}_{t}^{r, p 1}, \mathbf{d}_{t}^{r, p 2}, \mathbf{d}_{t}^{r, p 3}$ & $\begin{array}{l}\text { Most, second-most and third-most preferred option of unit } r \text { in } t \\
\quad \text { elements of set (list) } L_{t}^{r}\end{array}$ \\
\hline$e^{r, \text { own }}, e^{r, \text { res }}$ & $\begin{array}{l}\text { Errors made by head of unit } r \text { in perceiving the components } P^{r \text {,own }} \text { and } P^{r \text {,res }} \\
\quad \text { respectively, of the value base for compensation }\end{array}$ \\
\hline$f_{i}$ & $\begin{array}{l}\text { Function that gives the performance contribution } C_{i t} \text { of a single choice } i \text { and, } \\
\text { eventually, } K \text { other choices } j \neq i\end{array}$ \\
\hline$i, j$ & Indices for the single choice of the $N$-dimensional decision vector $\mathbf{d}_{t}$ \\
\hline$K$ & Number of choices $d_{j t}, j \neq i$ which affect the contribution $C_{i t}$ of choice $d_{i t}$ \\
\hline$K^{*}$ & Level of cross-unit interactions \\
\hline$L_{t}^{r}$ & $\begin{array}{l}\text { List (set) of unit } r \text { 's preferences consisting of the first, second-most and } \\
\text { third-most preferred option in time step } t\end{array}$ \\
\hline$M$ & Number of departments of the organization \\
\hline$N$ & Number of binary choices to be made \\
\hline$N^{r}$ & Number of binary choices to be made by department $r$ \\
\hline$p\left(\alpha^{a}, t\right)$ & Probability of incentive system $\alpha^{a}$ to be implemented in time step $t$ \\
\hline$P_{t}^{r}\left(\mathbf{d}_{t}\right)$ & Value base for compensation of head of department $r$ in period $t$ \\
\hline$P_{t}^{r, \text { own }}, P_{t}^{r, \text { res }}$ & $\begin{array}{l}\text { Value base for compensation of department } r \text { 's head resulting from choices } \\
\text { assigned to department } r \text { (own), respectively from performance achieved } \\
\text { by departments other than } r \text { (res) }\end{array}$ \\
\hline$\tilde{P}^{r}, \tilde{P}^{r, \text { own }}, \tilde{P}^{r, \text { res }}$ & $\begin{array}{l}\text { Value base for compensation and its components, respectively as perceived } \\
\text { by head of department } r\end{array}$ \\
\hline$q, r, s$ & Indices for departments \\
\hline$t$ & Time step/period within the observation period $T$ \\
\hline$T$ & Observation period \\
\hline$T^{*}$ & $\begin{array}{l}\text { Number of periods after which the incentive system is evaluated and eventually } \\
\text { altered }\end{array}$ \\
\hline$v$ & Aspiration level within reinforcement learning \\
\hline$V_{t}$ & Overall performance of an organization achieved in period $t$ \\
\hline$\tilde{V}_{t}$ & $\begin{array}{l}\text { Overall performance of an organization as ex ante perceived by the headquarters } \\
\text { for period } t\end{array}$ \\
\hline$w$ & $\begin{array}{l}\text { Auxiliary variable, number of choices assigned to departments } s \text { other than } r \text {, } \\
\text { with } s \prec r\end{array}$ \\
\hline
\end{tabular}

\section{References}

[1] Altenberg, L., Section B2.7.2, NK Fitness Landscapes, in Handbook of Evolutionary Computation, eds. Bäck, T., Fogel, D. and Michalewicz, Z. (Oxford University Press, Oxford, 1997), pp. B2.7:5-B2.7:10.

[2] Axelrod, R., The Evolution of Cooperation (Basic Books Inc., New York, 1984).

[3] Axtell, R., What economic agents do: How cognition and interaction lead to emergence and complexity, Rev. Austrian Econ. 20 (2007) 105-122. 
[4] Banker, R. D. and Datar, S. M., Sensitivity, precision, and linear aggregation of signals for performance evaluation, J. Account. Res. 27 (1989) 21-40.

[5] Bedford, D. S. and Malmi, T., Configurations of control: An exploratory analysis, Manag. Account. Res. 27 (2015) 2-26.

[6] Brenner, T., Agent learning representation: Advice on modelling economic learning, in Handbook of Computational Economics, Vol. 2, eds. Tesfatsion, L. and Judd, K. L. (Elsevier, Amsterdam, 2006), pp. 895-947.

[7] Bush, R. R. and Mosteller, F., Stochastic Models for Learning (Wiley, Oxford, 1955).

[8] Bushman, R. M., Indjejikian, R. J. and Smith, A., Aggregate performance measures in business unit manager compensation: The role of intrafirm interdependencies, J. Account. Res. 33 (1995) 101-129 (Supp.).

[9] Chang, M.-H. and Harrington, J. E., Agent-based models of organizations, in Handbook of Computational Economics, Vol. 2, eds. Tesfatsion, L. and Judd, K. L. (Elsevier, Amsterdam, 2006), pp. 1273-1337.

[10] Davila, T., An exploratory study on the emergence of management control systems: Formalizing human resources in small growing firms, Accoun. Organ. Soc. 30 (2005) 223-248.

[11] Davis, J. P., Eisenhardt, K. M. and Bingham, C. B., Developing theory through simulation methods, Acad. Manage. Rev. 32 (2007) 480-499.

[12] Dosi, G., Levinthal, D. and Marengo, L., Bridging contested terrain: Linking incentivebased and learning perspectives on organizational evolution, Ind. Corp. Change 12 (2003) 413-436.

[13] Drazin, R. and Van de Ven, A. H., Alternative forms of fit in contingency theory, Adm. Sci. Q. 30 (1985) 514-539.

[14] Eisenhardt, K. M., Agency theory: An assessment and review, Acad. Manag. Rev. 14 (1989) 57-74.

[15] Epstein, J. M., Agent-based computational models and generative social science, in Generative Social Science: Studies in Agent-based Computational Modeling, ed. Epstein, J. M. (Princeton University Press, Princeton, 2006), pp. 4-46.

[16] Galbraith, J. R., Organization design: An information processing view, Interfaces 4(3) (1974) 28-36.

[17] Gilbert, N. and Troitzsch, K. G., Simulation for the Social Scientist, 2nd edn. (Open University Press, Buckingham, 2005).

[18] Grabner, I. and Moers, F., Management control as a system or a package? Conceptual and empirical issues, Account. Organ. Soc. 38 (2013) 407-419.

[19] Guerrero, O. A. and Axtell, R., Using agentization for exploring firm and labor dynamics: A methodological tool for theory exploration and validation, in Emergent Results of Artificial Economics, LNEMS, Vol. 652, eds. Osinga, S., Hofstede, G. J. and Verwaart, T. (Springer, Berlin, 2011), pp. 139-150.

[20] Kanfer, R., Motivation theory and industrial/organizational psychology, in Handbook of Industrial and Organizational Psychology, Vol. 1, eds. Dunnette, M. D. and Hough, L. (Consulting Psychologists Press, Palo Alto, 1990), pp. 75-170.

[21] Kauffman, S. A. and Levin, S., Towards a general theory of adaptive walks on rugged landscapes, J. Theor. Biol. 128 (1987) 11-45.

[22] Lambert, R. A., Contracting theory and accounting, J. Account. Econ. 32 (2001) 3-87.

[23] Law, A. M., Simulation Modeling and Analysis, 4th edn. (McGraw-Hill, New York, 2007).

[24] Levitan, B. and Kauffman, S. A., Adaptive walks with noisy fitness measurements, Mol. Divers. 1 (1995) 53-68. 
[25] Li, R., Emmerich, M. T. M., Eggermont, J., Bovenkamp, E. G. P., Bäck, T., Dijkstra, J. and Reiber, J. H. C., Mixed-integer NK landscapes, in Parallel Problem Solving from Nature - PPSN IX, LNCS, Vol. 4193, eds. Runarsson, T. P., Beyer, H.-G., Burke, E. et al. (Springer, Berlin, 2006), pp. 42-51.

[26] Locke, E. A. and Latham, G. P., Building a practically useful theory of goal setting and task motivation: A 35-year odyssey, Am. Psychol. 57 (2002) 705-717.

[27] Lorscheid, I., Heine, B.-O. and Meyer, M., Opening the black box of simulations: Increased transparency and effective communication through the systematic design of experiments, Comput. Math. Organ. Theory 18 (2012) 22-62.

[28] Malmi, T. and Brown, D. A., Management control systems as a package: Opportunities, challenges and research directions, Manag. Account. Res. 19 (2008) 287-300.

[29] Malone, T. W. and Crowston, K., The interdisciplinary study of coordination, ACM Comput. Surv. 26 (1994) 87-119.

[30] Merchant, K. A. and Van der Stede, W. A., Management Control Systems: Performance Measurement, Evaluation and Incentives, 3rd edn. (Prentice Hall, Harlow, 2012).

[31] Murphy, K. J., Performance standards in incentive contracts, J. Account. Econ. 30 (2000) 245-278.

[32] Rivkin, J. W. and Siggelkow, N., Patterned interactions in complex systems: Implications for exploration, Manag. Sci. 53 (2007) 1068-1085.

[33] Safarzynska, K. and van den Bergh, J., Evolutionary models in economics: A survey of methods and building blocks, J. Evol. Econ. 20 (2010) 329-373.

[34] Sah, R. K. and Stiglitz, J. E., The architecture of economic systems: Hierarchies and polyarchies, Am. Econ. Rev. 76 (1986) 716-727.

[35] Siggelkow, N., Misperceiving interactions among complements and substitutes: Organizational consequences, Manag. Sci. 48 (2002) 900-916.

[36] Siggelkow, N. and Rivkin, J. W., Speed and search: Designing organizations for turbulence and complexity, Organ. Sci. 16 (2005) 101-122.

[37] Simon, H. A., A behavioral model of rational choice, Q. J. Econ. 69 (2005) 99-118.

[38] Thompson, J. D., Organizations in Action: Social Science Bases of Administrative Theory (McGraw-Hill, New York, 1967).

[39] Wall, F., The (Beneficial) Role of informational imperfections in enhancing organisational performance, in Progress in Artificial Economics, LNEMS, Vol. 645, eds. Li Calzi, M., Milone, L. and Pellizzari, P. (Springer, Berlin, 2010), pp. 115-126.

[40] Wall, F., Agent-based modeling in managerial science: An illustrative survey and study, Rev. Manag. Sci. 10 (2016) 135-193.

[41] Welch, B. L., The significance of the differences between two means when the population variances are unequal, Biometrika 25 (1938) 350-362. 